\title{
Use of an Electroacoustic Device and Bone Densitometry in the Diagnosis of Osteoporosis: Utility, Validation, and Comparison
}

\author{
Teodoro Cordova-Fraga1*, Martha Alicia Hernandez-Gonzalez², Angelica Hernandez-Rayas ${ }^{1}$, \\ Daniel Alberto Ponce-Covarrubias ${ }^{2}$ \\ ${ }^{1}$ Departamento de Ingeniería Física-DCI, Universidad de Guanajuato campus León Loma del Bosque N. 103, Lomas del \\ Campestre, León, GTO, Mexico \\ ${ }^{2}$ IMSS Unidad Médica Alta Especialidadclínica T1 Bajío. Blvd. Adolfo López Mateos S/N, Los Paraísos, León, GTO, Mexico \\ Email: *theo@dci.ugto.mx, martha_hdz@hotmail.com, angelicahr@fisica.ugto.mx, daniel_pc56@hotmail.com
}

How to cite this paper: Cordova-Fraga, T., Hernandez-Gonzalez, M.A., HernandezRayas, A. and Ponce-Covarrubias, D.A. (2020) Use of an Electroacoustic Device and Bone Densitometry in the Diagnosis of Osteoporosis: Utility, Validation, and Comparison. Open Journal of Applied Sciences, 10, 210-218.

https://doi.org/10.4236/ojapps.2020.105016

Received: April 7, 2020

Accepted: May 10, 2020

Published: May 13, 2020

Copyright $\odot 2020$ by author(s) and Scientific Research Publishing Inc. This work is licensed under the Creative Commons Attribution International License (CC BY 4.0).

http://creativecommons.org/licenses/by/4.0/

\begin{abstract}
According to the World Health Organization (WHO), men and women older than 50 years present osteoporosis with reduced bone mass, this is one of the major impact morbidities causes in the world. It may be present in the hip, spine, and wrist. The gold standard technique for osteoporosis diagnosis is the Bone Densitometry (DXA). The evaluation of an electroacoustic device is as an alternative procedure for the validation and diagnosis of osteoporosis. Diagnosis of osteoporosis severity was carried out in 49 females by using the registers of the DEXA's T-Score values. These were statistically compared with the measurements performed using the electroacoustic device. Non-Significative difference between measurements was found with ANOVA and Chi-square tests and the area for the ROC curve on electroacoustic devices was 0.551. The Bland Altman suggests an excellent concordance between both techniques. This is a non-invasive method that has a proper match with the gold standard. The study suggests that procedure measurements with the electroacoustic device could be implemented as an alternative clinical practice for osteoporosis diagnosis.
\end{abstract}

\section{Keywords}

Electroacoustic Device, New Diagnostic Tests, Densitometry

\section{Introduction}

The Mexico country is in an epidemiological transition represented by a rise in chronic degenerative diseases. The osteoporosis disease is one of the causes with 
major morbidity impact in this country. It may be present in any skeletal area, such as the hip or spine, though it is most likely that the wrists are affected. According to the World Health Organization (WHO) population studies, men and women older than 50 years present reduced bone mass and osteoporosis as follows. For males, the rate is $39 \%$ and $44 \%$ in the column and in the hip for males, respectively. For women, the osteoporosis rate is $59 \%$ for both regions [1].

The osteoporosis is defined as a systemic disease of the skeleton, characterized by the decrease of bone density with the deterioration of bone tissue leading to an increased risk of bone fragility and fracture. This already has become a public health problem on a world level, with a $30 \%$ increase in morbidity and mortality and with an estimated economic impact around \$25 trillion dollars per year [2].

Currently, the gold standard technique for osteoporosis diagnosis is the absorptiometry of X-ray of dual energy, also called Bone Densitometry (DXA). This does expose the patient to ionizing radiation, even though the dose of ionizing radiation is relatively small [3] [4] [5]. The test result is determined by the T-score parameter that values fracture risks. Another diagnosis method is the Digital X-ray radiogrammetry (DXR), which presents a low sensitivity and poor predictive utility, as well as a high cost [4]-[12].

An alternative procedure for this type of evaluation is the diagnosis by using electroacoustic device [13] [15], which one uses sound transmission for diagnosis of bone alterations. So, in this work, an alternative procedure for validation and diagnosis of osteoporosis is proposed by using sound transmission.

An alternative procedure for this type of evaluation is the diagnosis by using an electroacoustic device [13] [15], which one uses sound transmission for diagnosis of bone alterations. So, in this work, an alternative procedure for validation and diagnosis of osteoporosis is proposed by using the sound transmission.

\section{Methodology}

\subsection{Electroacoustic Device}

The electroacoustic device has already been used for the diagnosis of congenital hip dislocation in newborns [13] [14] [15]. The setup of the electroacoustic system is shown in Figure 1 schematic: (a) Tip of the device for the stimulus signal generation (b) Femoral head, (c) Tip of the device for the signal acquisition, (d) Pubis and (e) Graphical interface module where it is selected the operates frequency and time of measurement.

The physics principle of sound propagation suggests that the acoustic effect through porous solid material is different than through a less porous solid of the same material. So, when the generated acoustic signal travels through the bone under study, the signal changes in the amplitude are used to diagnose osteoporosis severity.

This device was adjusted to operate, in this study, at a frequency of $256 \mathrm{~Hz}$. The out values were presented in decibels. It was established that the power change of a healthy bone is different from the power and frequency of a bone with osteoporosis. 


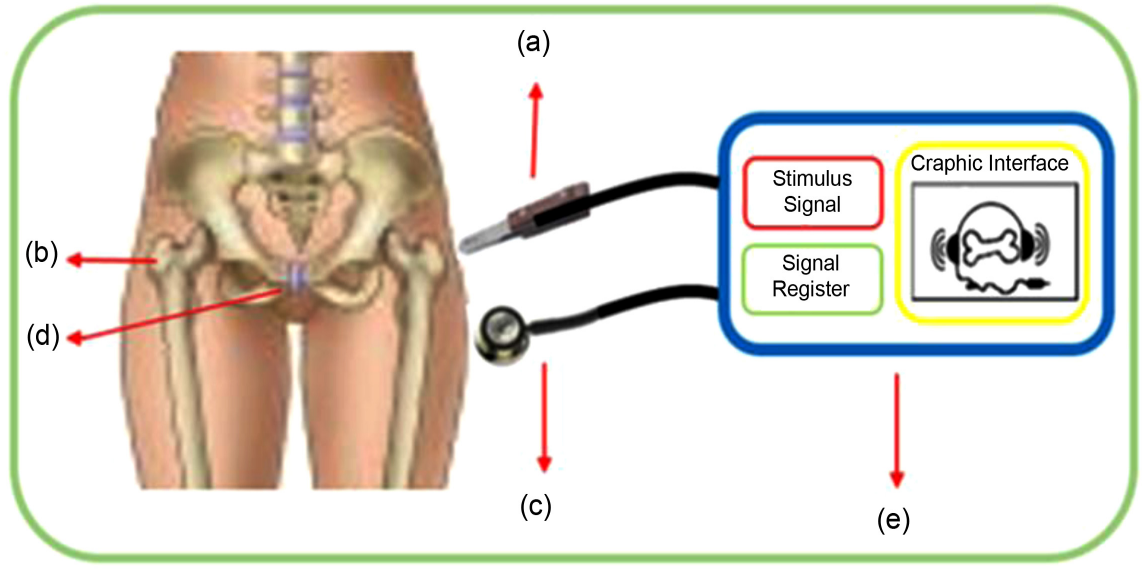

Figure 1. Schematic of the system. (a) Tip of the device for the signal generating, (b) Femoral bone head, (c) Tip of the device for the signal acquisition, (d) Pubis and (e) Graphic interface.

\subsection{Participants' Inclusion Criterions in This Study}

This is a cross-sectional, analytical, diagnostic test for patients with clinical suspicion and an X-ray indicative of osteoporosis. All the enrolled subjects in the study signed an informed consent letter. The study group included 45 female patients from 40 to 92 years, all with diagnostic suspicion of osteoporosis. All them were patients of the endocrinology clinic at the High Specialty medical unit of the Bajío N. 1 hospital of the Mexican Institute of Social Security (IMSS), in León cityin Guanajuato (GTO). The inclusion criteria left out those patients with morbid obesity, incomplete studies of densitometry, pregnancy and those who had undergone a study with contrast medium and/or nuclear medicine $48 \mathrm{~h}$ before this measurement study. Subjects with hip prostheses were also excluded.

The sample size was calculated according to the report by Amiri L, et al., (2017) [9] where a correlation coefficient $r=0.69$ was found for densitometry and the presence of osteoporosis in a female population. A sample size of $45 \mathrm{pa}-$ tients was obtained, based on the assumption that the correlation coefficient for an adequate diagnostic test should be equal to or greater than 0.70 , a test power of $80 \%$, a significance level of $0.05 \%$ and $20 \%$ of non-responding potentials.

\subsection{Statistical Analysis}

The measurements of the subject were arranged in three groups for the statistical analysis: (a) Healthy, (b) Osteopenia, and (c) osteoporosis. The results obtained were compared for qualitative variables by Chi-Square and for quantitative by the Student's t-test for independent samples.

The severity of the osteoporosis records was classified according to the method of Amiri L et al., (2017) [9]

- Osteoporotic: $\mathrm{T}-$ score $\leq-2.5$,

- Osteopenic: $-2.5<\mathrm{T}-$ score $<-1$,

- Normal: $-1 \leq \mathrm{T}-$ score. 
A comparison of the severity of the osteoporosis records among the electroacoustic device measurements and the T-score values on the Densitometry technique evaluations were done. We used the correlation coefficient of Pearson through the area under the ROC curve with their respective confidence intervals by the method of Hanley/McNeil and the cut point. Finally, the Bland-Altman analysis was performed for the magnitude of concordance between both methods.

In all statistical tests: ANOVA, Chi-Square and multiple correlations were done. A significance value of $\alpha=0.05$ was considered.

\subsection{Ethical Aspects}

This study was authorized by the Research and Ethics Committee of the High Specialty Medical Unit Bajío No. 1. of the IMSS, under registration number R-2017-1001-37. This research project complies with the principles of non-maleficence, fairness, and fairness of the regulation of the General Health Law and international Codes of ethics, the Helsinki declaration of the World Medical Association. This research is of minimum risk, Using the electroacoustic device is a non-invasive procedure for the frequency and power used, furthermore to date there are no reports of adverse events.

\section{Results}

Table 1 shows a summary of the participating group. There is no significant statistical difference among the main demographic variables and groups.

The ANOVA test and the Chi-Square test showed no significant difference between the two samples, except for the severe osteoporosis group that was treated as osteoporosis.

The correlation coefficient of Pearson $(r)$ was performed for the absolute values of the femoral densitometry, column, and radius of the electroacoustic device, using a value of $r$ less than 0.50 in all cases.

The concordance of different means and standard deviations are observed in the Bland Altman analysis. The frequency in Hertz of electroacoustics was compared to T-score the proximal femoral level: $95 \%$ of patients were within these values (see Figure 2). Only two cases in the sample fell out of this confidence interval -4.4 and -9.2 . According to this, the electroacoustic device underestimates the valueof the femur at 6.8 (see Figure 2).

Finally, the analysis under the ROC curve of the electroacoustic device measurements shows an area of 0.551 , where the cutoff point value for the frequency in Hertz to define osteoporosis is less equal than $4.4(\leq 4,4)$ with a sensitivity of $58 \%$ and specificity of $72 \%$ (see Figure 3 ).

The ANOVA was performed for the comparison of averages and the post hoc analysis of Bonferroni showed a clear difference between the groups with respect to the value of $\mathrm{T}$-score and Z-score of the femur (see Table 2). This was not the case for the column. Although there is no statistical difference with the values of 
Hertz obtained by the device, there is a clear trend toward greater transmission of sound with more osteoporosis.

Table 1. Demographic characteristics of the participants.

\begin{tabular}{|c|c|c|c|c|}
\hline Group & $\begin{array}{c}\text { Normal Level } \\
\qquad N=3\end{array}$ & $\begin{array}{l}\text { Osteopenia } \\
\qquad N=30\end{array}$ & $\begin{array}{c}\text { Osteoporosis } \\
\quad N=10\end{array}$ & $\begin{array}{l}\text { Osteoporosis } \\
\text { Severe } N=2\end{array}$ \\
\hline $\begin{array}{l}\text { Age in years (median and } \\
\text { range) }\end{array}$ & $61(50-70)$ & $64.1(40-83)$ & $73.4(53-92)$ & $66.5(64-69)$ \\
\hline \multicolumn{5}{|l|}{ Occupation $(n \%)$} \\
\hline Housewife & $3(100)$ & $23(76.6)$ & $9(90)$ & $1(50)$ \\
\hline Employee & 0 & $7(23.4)$ & $1(10)$ & $1(50)$ \\
\hline \multicolumn{5}{|l|}{ Residence Place $(n \%)$} \\
\hline León & $2(66.6)$ & $28(93.3)$ & $7(70)$ & $2(100)$ \\
\hline Guanajuato & 0 & 0 & $1(10)$ & 0 \\
\hline Salamanca & 0 & $1(3.3)$ & 0 & 0 \\
\hline Moroleón & 0 & 0 & $1(10)$ & 0 \\
\hline Silao & 0 & $1(3.3)$ & 0 & 0 \\
\hline San Fco. del Rincón & $1(33.3)$ & 0 & 0 & 0 \\
\hline \multicolumn{5}{|l|}{ Associated Diseases $(n \%)$} \\
\hline $\mathrm{Dm}^{2}$ & 0 & $6(20)$ & $1(10)$ & $1(50)$ \\
\hline Hypertension & 0 & $14(46.6)$ & $5(50)$ & $1(50)$ \\
\hline Rheumatoid arthritis & 0 & $3(10)$ & 0 & 0 \\
\hline Hypothyroidism & $3(100)$ & $2(6.6)$ & $1(10)$ & $1(50)$ \\
\hline Other & 0 & $12(40)$ & $4(40)$ & 0 \\
\hline Any & 0 & $6(20)$ & $3(30)$ & 0 \\
\hline $\begin{array}{l}\text { Diagnosis Time in years } \\
\text { (median and range) }\end{array}$ & $2.6(1-5)$ & $\begin{array}{c}4.41 \\
\text { (1 month-14 Yrs) }\end{array}$ & $6.5(1-20)$ & $3(1-5)$ \\
\hline \multicolumn{5}{|l|}{ Treatment ( $n \%)$} \\
\hline Raloxifene & 0 & $5(16.6)$ & $2(20)$ & 0 \\
\hline Zoledronic acid & 0 & 0 & $2(20)$ & $1(50)$ \\
\hline Denosumab & 0 & $2(6.6)$ & 0 & 0 \\
\hline Risedronate & $3(100)$ & $17(56.6)$ & $6(60)$ & $1(50)$ \\
\hline Only Calcium & 0 & $4(13.3)$ & 0 & 0 \\
\hline Without TTO & 0 & $2(6.6)$ & 0 & 0 \\
\hline
\end{tabular}

Table 2. Result comparison for bone densitometry vs. electroacoustic device among groups.

\begin{tabular}{ccccc}
\hline & $\begin{array}{c}\text { Normal } \\
\text { Group } N=3\end{array}$ & $\begin{array}{c}\text { Osteopenia } \\
N=30\end{array}$ & $\begin{array}{c}\text { Osteoporosis } \\
N=12\end{array}$ & $p$-value \\
\hline $\begin{array}{c}\text { Femur densitometry } \\
T-\text { Score }\end{array}$ & $-0.70 \pm 0.10$ & $-1.88 \pm 0.54$ & $-2.517 \pm 1.13$ & 0.001 \\
$Z$ - Score & $0.40 \pm 0.55$ & $-0.44 \pm 0.69$ & $-0.95 \pm 0.92$ & 0.036 \\
$\begin{array}{c}\text { Column Densitometry } \\
T-\text { Score }\end{array}$ & $-1.70 \pm 0.51$ & $-2.30 \pm 1.19$ & $-2.80 \pm 1.29$ & 0.481 \\
$Z$ - Score & $-0.16 \pm 1.00$ & $-0.63 \pm 1.40$ & $-0.84 \pm 1.25$ & 0.678 \\
Frequency of & & & & \\
Electroacoustic & $4.36 \pm 1.34$ & $4.60 \pm 1.11$ & $4.96 \pm 0.94$ & \\
\hline
\end{tabular}




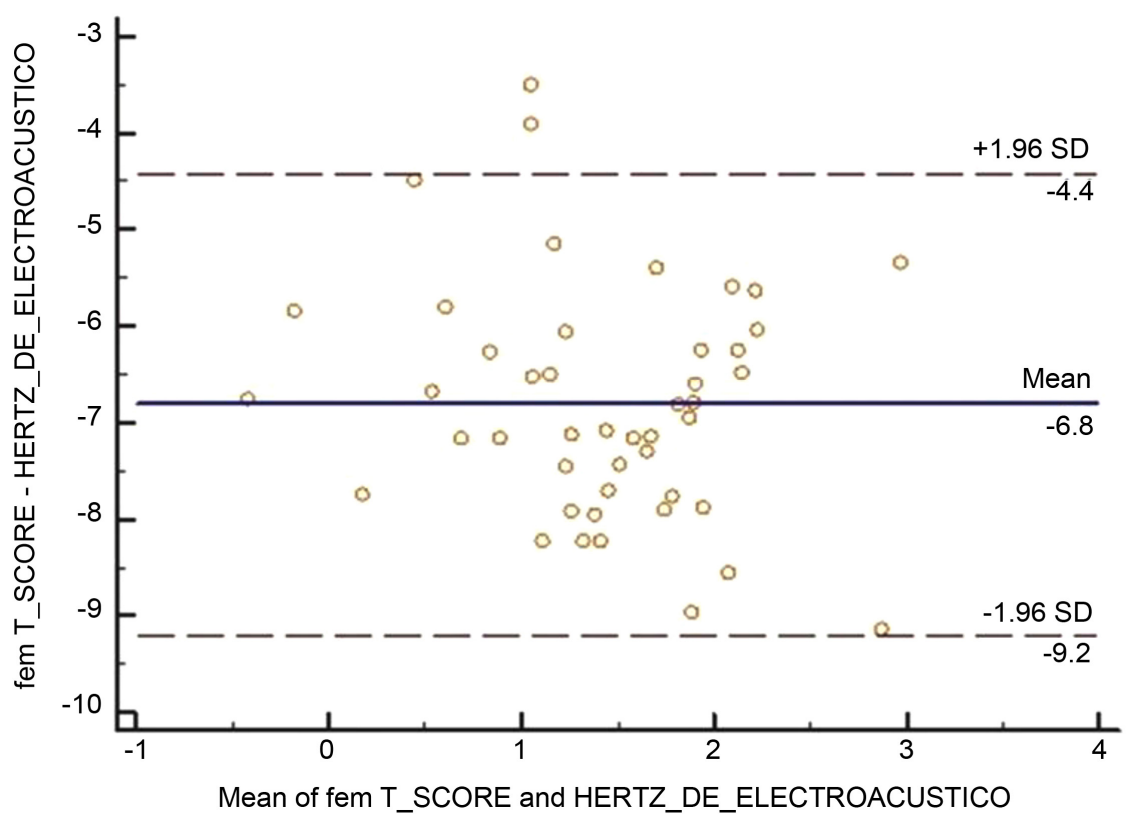

Figure 2. Bland-Altman analysis between the Electroacoustic device values and the T-Score of the Bone densitometry femur.

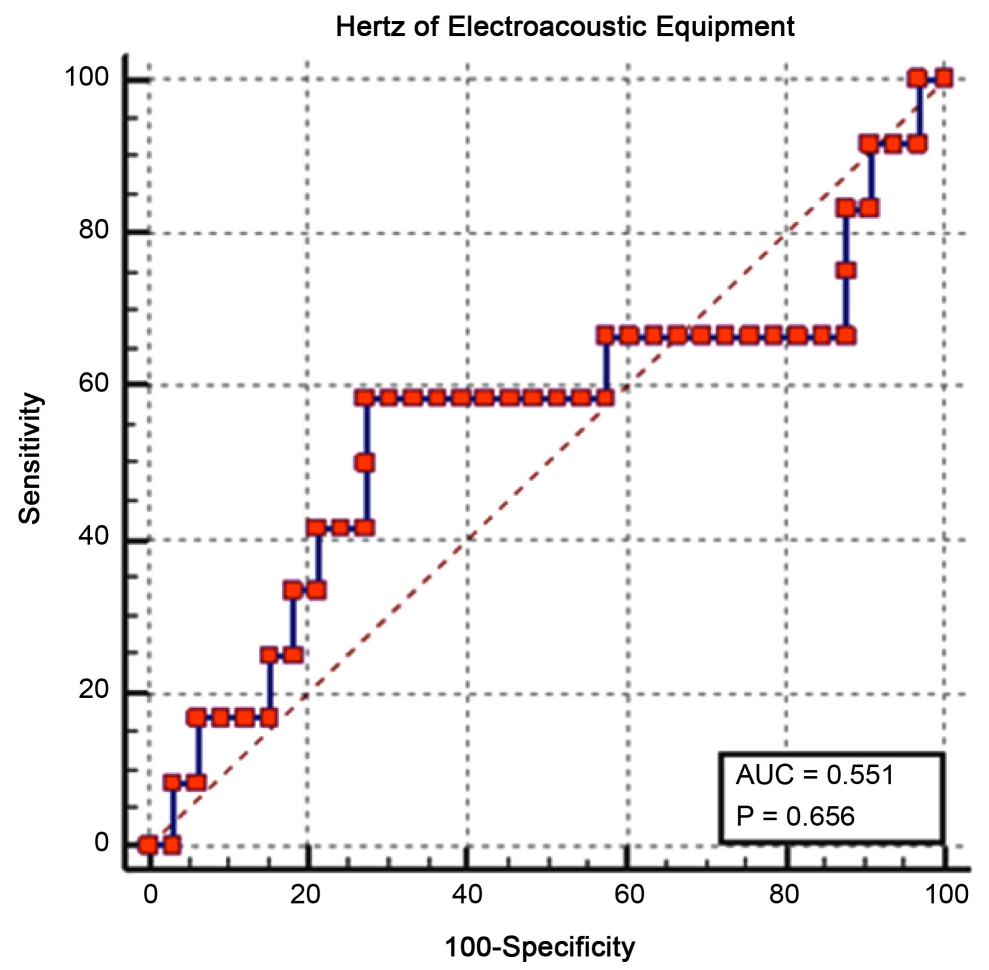

Figure 3. The area under the ROC curve of the Electroacoustic device for the determination of osteoporosis.

\section{Discussion}

An analysis of the Albrecht W Popp et al., (2013) [11] and Senn C et al., (2014) [12] have made it clear that the dual-energy $\mathrm{X}$-ray Absorption is an excellent di- 
agnostic technique for diagnosing osteoporosis, furthermore, the United States Preventive Services Working Group currently recommends the detection of osteoporosis with DXA in women aged 65 years or older, as well as in younger women at risk of Fracture. It is not yet clear how and in whom the screening study should be carried out for the timely monitoring and detection of risk patients [16].

On the other hand, the electroacoustic device is an innovation from the University of Guanajuato, which emits sound at a certain frequency in, for example, one end of the femoral bone and captures the signal in the pubis bone. The acoustic signal travels through the femur and hip to the pubis bone: power changes and/or frequency behavior in the measurements can be used to diagnose the possibility of hip dysplasia and/or osteoporosis.

The evaluation of this non-invasive method shows promise for discriminating between healthy and osteoporotic bone: specificity above 70\%. While it does not show a statistical correlation, the method has a proper match with the gold standard.

\section{Conclusion}

The electroacoustic device is non-invasive, safe, without side effects, and portable. Although it tends to underestimate the degree of osteoporosis, it promises to be useful as a screening procedure to discriminate between healthy and sick bone with specificity above $70 \%$. However, it is that we suggest the need to do prospective research studies with a greater number of patients and different stages of the disease.

\section{Acknowledgements}

Authors thank the University of Guanajuato by the partial support under grant DAIP/2019/59023, also to all patients enrolled in this study, to the IMSS-Hospital for the facilities and finally, the English translation of this manuscript was reviewed by Gavin O'Mahony MD form the Guthrie Medical Center, Corning, New York.

\section{Conflicts of Interest}

The authors declare no conflicts of interest regarding the publication of this paper.

\section{References}

[1] Peña-Ríos, D. (2015) Consenso de diagnóstico y tratamiento de la osteoporosis en la mujer postmenopáusica mexicana. Medicina Interna de México, 31, 596-610.

[2] Qassem, A. (2017) Treatment of Low Bone Density or Osteoporosis to Prevent Fractures in Men and Women: A Clinical Practice Guideline Update from the American College of Physicians. Annals of Internal Medicine, 166, 818-839. https://doi.org/10.7326/M15-1361

[3] Miller, P. (2017) The History of Bone Densitometry. Bone, 104, 4-6. 
https://doi.org/10.1016/j.bone.2017.06.002

[4] Edith Miranda, V., Sara Muñoz, C., Paola Paolinelli, G. and Claudia Astudillo, A. (2013) Bone Densitometry. Revista Médica Clínica Las Condes, 24, 169-173. https://doi.org/10.1016/S0716-8640(13)70142-1

[5] Orueta, R. and Gómez-Caro, S. (2010) Interpretation of Bone Mineral Densitometry. Medicina de Familia. SEMERGEN, 36, 1-60. https://doi.org/10.1016/j.semerg.2009.05.001

[6] Kälvesten, J., Lui, L.-Y., Brismar, T. and Cummings, S. (2016) Digital X-Ray Radiogrammetry in the Study of Osteoporotic. Bone, 86, 30-35. https://doi.org/10.1016/j.bone.2016.02.011

[7] Curtis, E.M., Moon, R.J., Harvey, N.C. and Cooper, C. (2017) The Impact of Fragility Fracture and Approaches to Osteoporosis Risk Assessment Worldwide. Bone, 104, 29-38. https://doi.org/10.1016/j.bone.2017.01.024

[8] White Van Gompel, E.C., Franks, P., Robbins, J.A. and Fenton, J.J. (2017) Incidence and Predictors of Repeat Bone Mineral Densitometry: A Longitudinal Cohort Study. Journal of General Internal Medicine, 32, 1090-1096.

https://doi.org/10.1007/s11606-017-4094-y

[9] Amiri, L., Kheiltash, A., Movassaghi, S., Moghaddassi, M. and Seddign, L. (2017) Comparison of Bone Density of Distal Radius with Hip and Spine Using dXA. Acta Medica Iranica, 55, 92-96.

[10] Lin, G.L., Wang, H., Dai, J., Li, X., Guan, M., Gao, S.T., Ding, Q., Wang, H.X. and Fang, H. (2017) Conjugated Linoleic Acid Prevents Age-Induced Bone Loss in Mice by Regulating Both Osteoblastogenesis and Adipogenesis. Biochemical and Biophysical Research Communications, 490, 813-820. https://doi.org/10.1016/j.bbrc.2017.06.122

[11] Popp, A.W., Guler, S., Lamy, O., Senn, C., Buffat, H., Perrelet, R., Hans, D. and Lippuner, K. (2013) Effects of Zoledronate versus Placebo on Spine Bone Mineral Density and Microarchitecture Assessed by the Trabecular Bone Score in Postmenopausal Women with Osteoporosis: A Three-Year Study. Journal of Bone and Mineral Research, 28, 449-454. https://doi.org/10.1002/jbmr.1775

[12] Senn, C., Günther, B., Popp, A.W., Perrelet, R., Hans, D. and Lippuner, K. (2014) Comparative Effects of Teriparatide and Ibandronate on Spine Bone Mineral Density (BMD) and Microarchitecture (TBS) in Postmenopausal Women with Osteoporosis: A 2-Year Open-Label Study. Osteoporosis International, 25, 1945-1951. https://doi.org/10.1007/s00198-014-2703-8

[13] Padilla-Raygoza, N., Medina-Alvarez, D., Ruiz-Paloalto, M.L., Cordova-Fraga, T., Sosa-Aquino, M.A. and Perez-Olivas, A.H. (2014) Diagnosis of Developmental Dysplasia of the Hip Using Sound Transmission in Neonates. Health, 6, 2510-2516. https://doi.org/10.4236/health.2014.618289

[14] Padilla-Raygoza, N., Diaz-Guerrero, R., Ruiz-Paloalto, M.L., Córdova, T., Sosa, M. and Huetzin Perez-Olivas, A. (2014) Validity and Reliability of a Measuring Device Based on Sound Transmission for Diagnosis of Hip Dysplasia in Newborns. Advances in Bioscience and Biotechnology, 5, 831-837.

https://doi.org/10.4236/abb.2014.510097

[15] Padilla-Raygoza, N., Olvera-Villanueva, G., Del Carmen Delgado-Sandoval, S., Cordova-Fraga, T., Sosa-Aquino, M.A. and Beltran-Campos, V. (2017) Validity and Reliability of Electroacoustic Probe for Diagnosis of Developmental Dysplasia of the Hip. BMC Pediatrics, 17, 149. https://doi.org/10.1186/s12887-017-0903-Z

[16] Brennan, O., Sweeney, J., O’Meara, B., Widaa, A., Bonnier, F., Byrne, H.J., 
O’Gorman, D.M. and O’Brien, F.J. (2017) A natural, Calcium-Rich Marine Multi-Mineral Complex Preserves Bone Structure, Composition and Strength in an Ovariectomised Rat Model of Osteoporosis. Calcified Tissue International, 101, 445-455. https://doi.org/10.1007/s00223-017-0299-7 